MEJUAJUA: Jurnal Pengabdian pada Masyarakat
https://www.jurnal.yaspenosumatera.org/index.php/mejuajua
Volume 1 | Nomor 2 | Desember |2021|Hal. 42-47
e-ISSN: 2807-2634

\title{
Optimalisasi Layanan Perpustakaan Sekolah Menggunakan Senayan Library Management System (SLiMS) Pada SMKS Ismailiyah
}

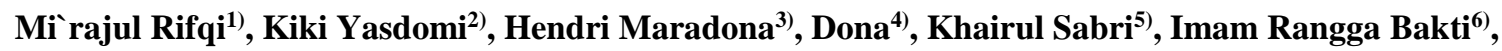 \\ Ridwan $^{7)}$, Ahmad AlbarSaragih ${ }^{8)}$ \\ 1,2,3,4,5,7,8 Sistem Informasi ,Fakultas Ilmu Komputer, Universitas Pasir pengaraian \\ ${ }^{6}$ Teknik Informatika,Fakultas Ilmu Komputer, Universitas Pasir pengaraian
}

Keywords :

Perpustakaan; SLiMS;

Sistem Informasi.

Corespondensi Author

Email: :

mirajulrifqi@gmail.com

History Artikel

Received: 08-12-2021

Reviewed: $13-12-2021$

Revised: $12-12-2021$

Accepted: 12-12-2021

Published: 20-12-2021

DOI:

10.52622/mejuajuajabdimas.v1i2.22

\begin{abstract}
Abstrak.
Perpustakaan SMK S Ismailiyah sudah berkembang cukup baik secara fisik, akan tetapi tidak adanya sumber daya manusia yang memiliki kompetensi dalam mengelola perpustakaan dan belum terotomatisasinya proses manajemen perustakaan di sekolah tersebut. Ketiadaan SDM dan manajemen yang baik pada SMK Ismailiyah menimbulkan permasalahan. Melihat permasalahan yang dihadapi oleh perpustakaan SMK S Ismailiyah, maka sosialiasi; penerapan; dan pelatihan Sistem Informasi Perpustakaan sangat diperlukan. Kegiatan pengabdian ini dilakukan dengan cara memberikan sosialiasi kepada pemangku kebijakan, kemudian memberikan pelatihan kepada pustakawan. Pelatihan kepada pustakawan diberikan dengan ceramah dan melakukan langsung melakukan praktik penggunaan SliMS.Dengan adanya penerapan sistem informasi perpustakaan dan pelatihan pustakawan ini dapat mengoperasikan SliMS untuk mengoptimalisasi pelayanan perpustakaan.
\end{abstract}

\section{PENDAHULUAN}

Perpustakaan adalah tempat yang menyediakan banyak buku sumber daya lain yang bisa diakses oleh masyarakat [1] untuk membaca, belajar, atau mendapatkan refrensi pada kehidupan sehari-hari mereka [2]. Bahan pustaka baik yang cetak seperti buku, jurnal, hasilpenelitian, skripsi, tesis, disertasi , terbitan berseri seperti koran, majalah, dan sebagainya, sedangkan non cetak seperti CD-ROM, jurnal elektronik, CD, Disket, Kaset dan lain sebagainya (Afrizal, 2019). Keberadaan perpustakaan di tengah kehidupan tentu akan membawa dampak pada perubahan kehidupan masyarakat [4]. Perpustakaan memiliki peranan strategis dalam mencerdaskan kehidupan anak bangsa [5]. Perubahan sosial akan selalu dilihat sebagai perkembangan, hal tersebut berbanding lurus dengan perkembangan perpustakaan [6]. Teknologi perpustakaan sering menjadi tolak ukur kemajuan dan modernisasi dari sebuah perpustakaan [7]. Apabila pengunjung perpustakaan tersebut merasa puas dengan pelayanan yang diterima, maka mereka pasti akan kembali untuk menggunakan perpustakaan sebagai media untuk memenuhi kebutuhan informasi mereka [8].

Sekolah Menengah Kejuruan Swasta Ismailiyah Rambah Hilir, Kabupaten Rokan Hulu sudah memiliki perpustakaan secara fisik, perpustakaan sudah berkembang cukup baik dengan adanya bantuan pemerintah dari berbagai Lembaga donasi kependidikan untuk pembangunan gedung perpustakaan 
dengan berbagai koleksi dan sarana prasarana, akan tetapi yang menjadi permasalahannya adalah tidak adanya sumber daya manusia yang memiliki kompetensi dalam mengelola perpustakaan dan belum terotomatisasinya proses manajemen perustakaan di sekolah tersebut.

Ketiadaan sumber daya manusia yang berkompeten untuk mengelola perpustakaan SMK S Ismailiyah Rambah Hilir tersebut juga berpengaruh pada menajemen pelayanan pada perpustakaan tersebut. Kekurangan layanan manajemen yang dimaksud berupa pengelolaan koleksinya belum optimal karena tidak sesuai dengan teori atau panduan pengelolaan koleksi. Permasalahan lain yang ditemui adalah tidak semua buku yang masuk ke perpustakaan didaftarkan ke dalam buku induk berdasarkan urutan masuknya buku tersebut ke perpustakaan, tanpa mempertimbangkan apakah buku tersebut buku lama atau buku baru. Hal ini gunanya untuk mengetahui seberapa banyak koleksi buku yang dimiliki perpustakaan. Adapun hal yang harus dicatat dalam inventarisasi adalah tanggal, nomor buku, judul buku, pengarang, penerbit, tahun terbit, tempat terbit, harga, dan keterangan. Selain itu, koleksi buku/bahan pustaka yang sampai di perpustakaan SMK S Ismailiyah Rambah Hilir belum diperiksa, apakah sudah sesuai dengan yang diminta atau tidak, setelah itu belum adanya pemeriksaan bentuk fisik buku, judul, pengarang, dan ciri-ciri lain yang dianggap perlu.

Kekurangan manajemen lainnya adalah pada proses peminjaman buku maupun pengembalian buku. Proses peminjaman dan pengembalian buku pada perpustakaan SMK S Ismailiyah Rambah Hilir masih dicatat di buku. Bahkan, terkadang proses peminjaman dan pengembalian buku tidak tercatat. Hal tersebut tentu menjadi kendala, contohnya banyak buku yang hilang karena tidak terdatanya proses peminjaman dan pengembalian buku. Selain itu, permasalahan yang tidak kalah pentingnya yang dihadapi perpustakaan adalah tidak terdatanya keanggotaan perpustakaan secara baik. Hal ini menjadi bermasalah, karena yang boleh melakukan peminjaman buku pada perpustakaan hanya bagi siswa dan guru yang sudah terdaftar menjadi anggota.

Permasalahan kekurangan manajemen yang dijelaskan di atas akan berujung pada buruknya laporan perpustakaan. Hal tersebut nyatanya dialami oleh perpustakaan, terbukti belum optimalnya laporan koleksi yang ada ada, peminjam, pendataan pengunjung. Buruknya laporan berkala pada pengambil keputusan tentu akan menjadi hal yang tidak baik dalam proses evaluasi perpustakaan di SMK S Ismailiyah Rambah Hilir.

Melihat permasalahan yang dihadapi oleh perpustakaan SMK S Ismailiyah Rambah Hilir, maka sosialiasi, penerapan dan pelatihan Sistem Informasi Perpustakaan sangat diperlukan. Software yang digunakan pada kegatan pengabdian ini adalah Senayan Library Management System (SLiMS). SLiMS adalah perangkat lunak sistem manajemen perpustakaan dengan sumber terbuka yang berbasis web dan gratis digunakan [9] [10]. SLiMS merupakan software yang didesain khusus untuk mempermudah pendataan koleksi perpustakaan, katalog, data anggota, transaksi dan sirkulasi koleksi perpustakaan. Sistem ini keseluruhannya bekerja secara sistematis sehingga dapat memperbaiki administrasi dan operasional perpustakaan serta dapat menghasilkan bentuk-bentuk laporan yang efektif dan berguna bagi menajemen perpustakaan.

\section{METODE}

Pelaksanaan Pengabdian Kepada Masyarakat berlangsung pada hari Rabu dan Kamis, tanggal 10 hingga 11 November 2021 yang dimulai pada jam 08.30 Wib sampai selesai, dihadiri oleh 2 orang pustakawan dari SMK S Ismailiyah Rambah Hilir. Kegiatan dilakukan di aula SMK S Ismailiyah Rambah Hilir. Adapun narasumber pengabdian ini adalah : 1) Mi rajul Rifqi, M.Cs, 2) Kiki Yasdomi, M.Kom, 3) Hendri Maradona, M.Kom, 3) Dona, M.Kom, dan 4) Khairul Sabri, M.Kom, 5) Imam Rangga Bakti, M.Kom dan 2 orang mahasiswa. Metode yang dipakai dalam upaya mencapai tujuan dalam pengabdian ini adalah melalui beberapa metode yaitu:

a. Metode sosialisasi, bertujuan untuk memberikan pemahaman tentang arti pentingnya pengelolaan layanan pada perpustakaan.

b. Metode praktek, yakni praktek menerapkan SliMS pada SMK S Ismailiyah Rambah Hilir

c. Metode pelatihan bertujuan untuk meningkatkan pengatahuan dan ketrampilan pustakawan dalam menggunakan aplikasi SliMS.

Dalam kegiatan ini, ada beberapa prosedur kerja yang akan dilakukan oleh Tim Pelaksana PKM, yaitu:

a. Tim PKM/para dosen menyusun rencana kerja yang tersistem dalam rancangan pembuatan penerapan SLiMS 
b. Tim PKM/dosen secara bersama-sama melakukan sosialisasi tahap 1 tentang pentingnya pemanfaatan layanan perpustakaan

c. Tim PKM/dosen menyediakan SliMS untuk mengoptimalkan pelayanan perpustakaan di SMK S Ismailiyah Rambah Hilir

d. Tim PKM/dosen melaksanakan pelatihan serta pendampingan dalam penggunaan SliMS bagi pustakawan di SMK S Ismailiyah Rambah Hilir.

\section{HASIL DAN PEMBAHASAN}

Pelaksanaan kegiatan penerapan SliMS dan pelatihan pustakawan sebagai sumber daya manusia di SMK S Ismailiyah Rambah Hilir berjalan sesuai dengan rencana. Sosialiasi diikuti oleh pimpinan di SMK S Ismailiyah Rambah Hilir untuk melihat proyeksi otomatisasi layanan perpustakaan yang dilakukan. Sedangkan pelatihan diikuti oleh dua orang tenaga kepustakawan SMK S Ismailiyah Rambah Hilir. Pelatihan ini di awali dengan memberikan materi sosialiasi mengenai pengelolaan perpustakaan dan aplikasi SliMS yang akan digunakan. Penyampaian materi mengenai penting pengelolaan perpustakaan yang baik kepada peserta disampaikan secara langsung di perpustakaan SMK S Ismailiyah Rambah Hilir. Penyampaian materi mengenai pengelolaan perpustakaan yang baik disampaikan dengan memberikan contoh pengelolaan tata letak buku, teknik pengklasifikasian buku, teknik pengkodean buku, dan teknik lain yang berkaitan dengan bentuk pengelolaan fisik perpustakan. Selain memberikan sosialiasi, dilakukan juga diskusi dengan peserta mengenai kelengkapan dan kebutuhan perpustakan di SMK S Ismailiyah Rambah Hilir.
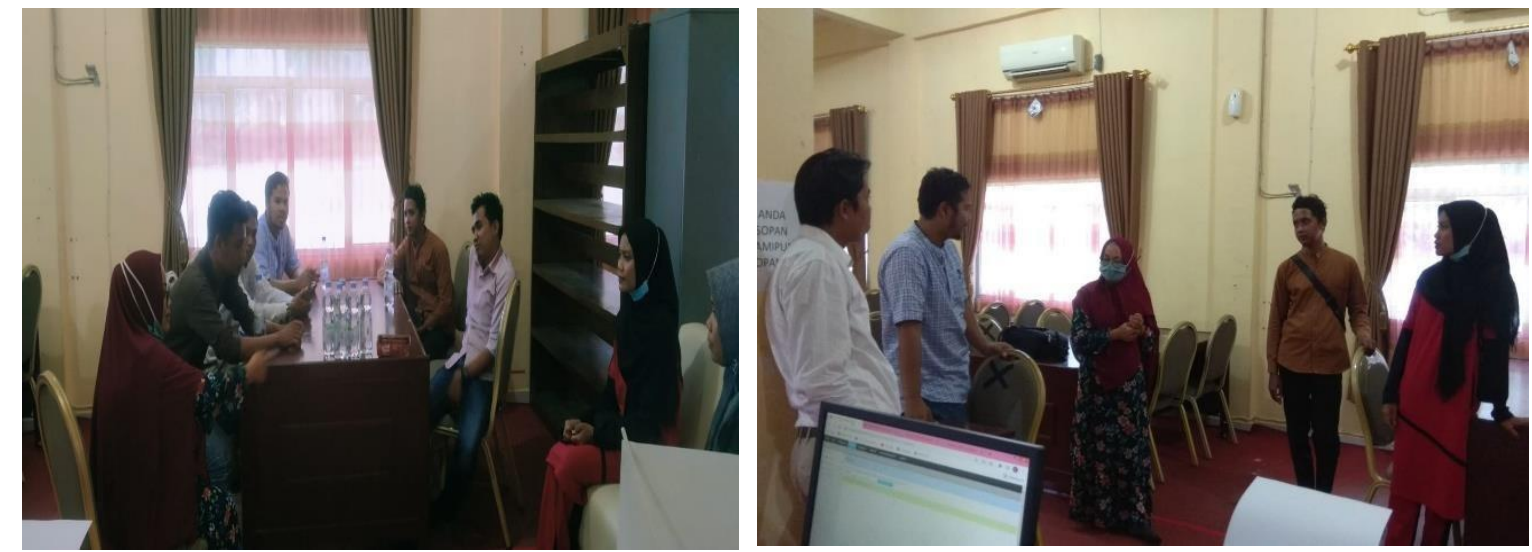

gambar 1 Diskusi kelengkapan dan kebutuhan perpustakaan

Setelah melakukan sosialiasi ke stake holder, tim melakukan persiapan implementasi Senayan Library Management System sesuai dengan kebutuhan dan keadaan pada perpustakaan di SMK S Ismailiyah Rambah Hilir. Tim mempersiapkan materi pengenalan SliMS yang akan diberikan kepada tenaga pustaka yang ada di SMK S Ismailiyah Rambah Hilir.

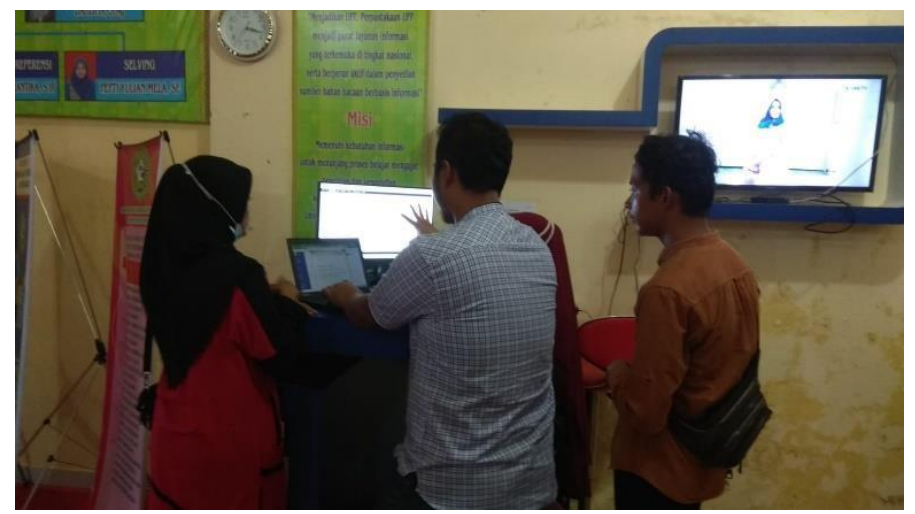

gambar 2. Pengenalan dan Pelatihan SLiMS 
Pada tahap selanjutnya, kegiatan pengabdian ini memberikan pelatihan kepada tanaga pustaka di SMK S Ismailiyah Rambah Hilir. Pelatihan ini dilakukan dengan langsung mempraktekkan penggunaan SliMS dengan pendampingan tim. Materi mengenai SliMS yang diberikan kepada peserta pelatihan adalah sebagai berikut.

\section{a. Bibliografi}

Kata bibliografi berasal dari bahasa Yunani dengan akar kata Biblion yang berarti buku dan Graphein yang berarti menulis. maka kata Bibliografi secara umum berarti penulisan buku. Dalam hal ini maka bibliografi berarti kegiatan teknis membuat deskripsi untuk suatu cantuman tertulis atau pustaka yang telah diterbitkan, yang tersusun secara sistematik berupa daftar menurut aturan yang dikehendaki. Dengan demikian tujuan bibliofrafi adalah untuk mengetahui adanya suatu buku/pustaka atau sejumlah buku/pustaka yang pernah diterbitkan. Pada materi ini, peserta diberikan pemahaman untuk melihat data buku, beserta pemahaman untuk melakukan penginputan buku pada SliMS. Tampilan bibliografi bisa dilihat pada gambar di bawah ini.

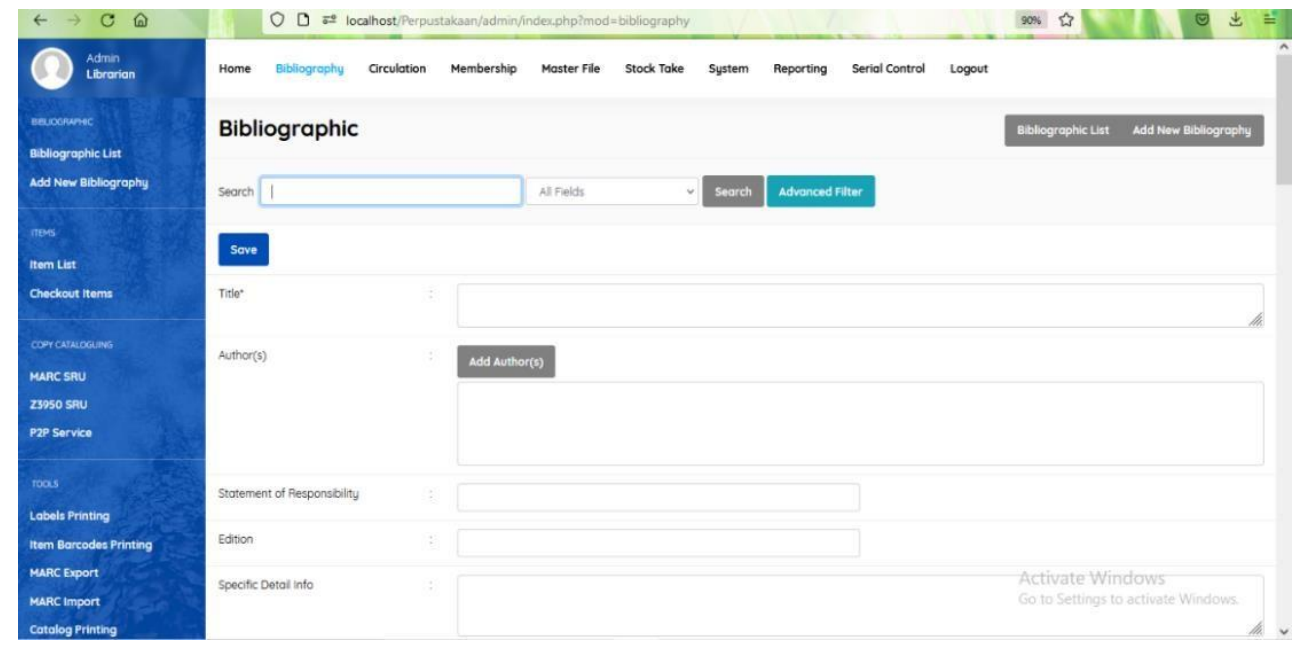

Gambar 3 Tampilan Bibliografi pada SLiMS

b. Keanggotaan

Setiap perpustakaan wajib membuat data pengunjung yang selalu memanfaatkan layan di Perpustakaan agar lebih memudahkan dalam hal pelayanan dan menaati peraturan/tata tertib pengguna fasilitas di perpustakaan di antaranya membuat daftar anggota kepada pemustaka yang berhak menggunakan fasilitas yang ada di perpustakaan. Pada materi ini, peserta diberikan pemahaman untuk melihat data anggota, beserta pemahaman untuk melakukan penginputan anggota baru SliMS. Tampilan keanggotaan pada SLiMS bisa dilihat pada gambar di bawah ini.

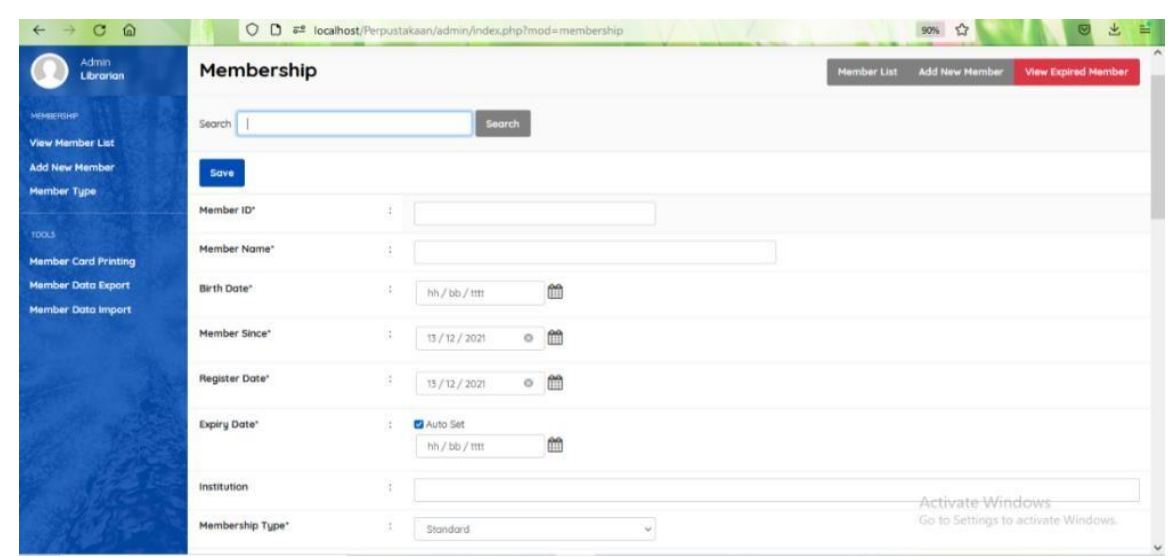

Gambar 4. Tampilan Keanggotaan pada SLiMS 
c. Transaksi Sirkulasi

Layanan sirkulasi bertujuan untuk membantu pemustaka dalam proses peminjaman, pengembalian, dan perpanjangan bahan pustaka. Prosedur layanan peminjaman dalam sirkulasi ini meliputi aktivitas pemilihan buku sampai buku bisa dipinjam oleh pemustaka dengan melalui proses peminjaman di bagian layanan sirkulasi. Sedangkan prosedur layanan pengembalian dan perpanjangan bahan pustaka ini meliputi aktivitas penyerahan pustaka yang dipinjam sampai dengan petugas memproses pengembalian ataupun perpanjangan pustaka di bagian layanan sirkulasi. Berikut tampilan sirkulasi pada SliMS.

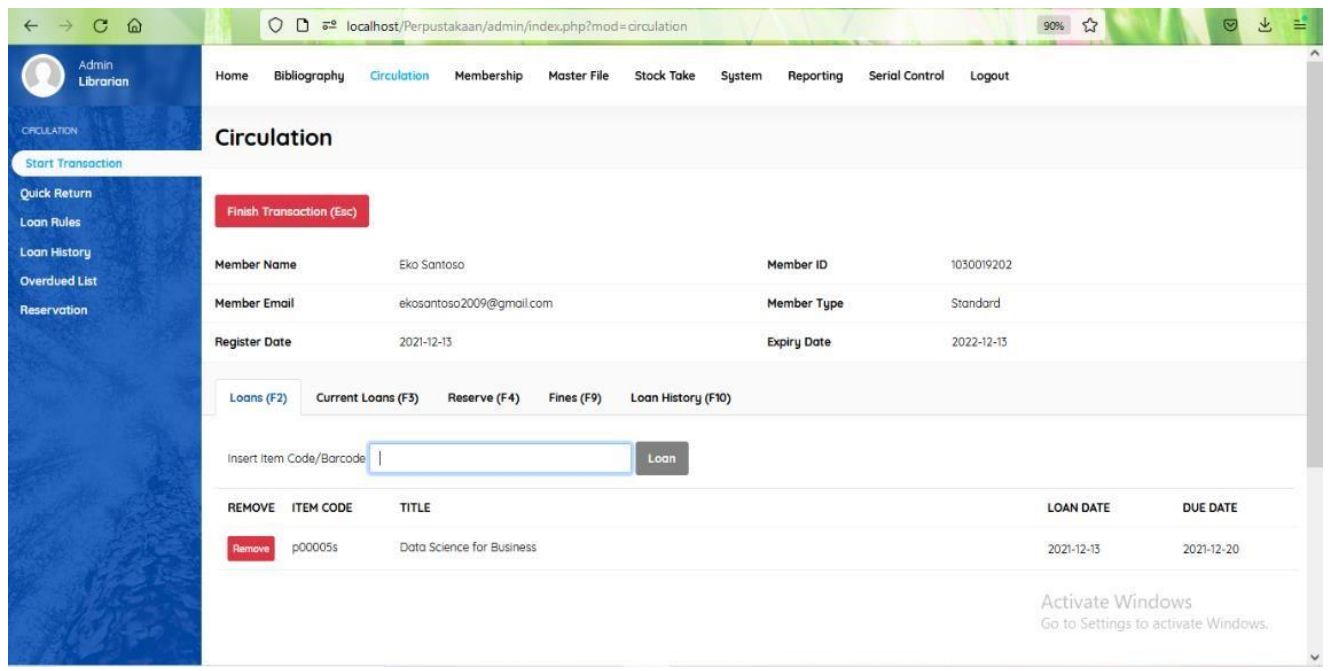

Gambar 5. Tampilan Transaksi Sirkulasi pada SLiMS

\section{KESIMPULAN}

Berdasarkan permasalahan dan pembahasan tersebut, maka pustakawan pada SMK S Ismailiyah Rambah Hilir yang mengikuti pelatihan tersebut mengetahui keadaan dan pemanfaatan Free Open Source Software(FOSS) berupa Senayan Library Management System (SliMS) yang diperoleh secara gratis. Dengan pengabdian ini juga, pustakawan SMK S Ismailiyah Rambah Hilir mampu mengoperasikan fitur-fitur yang ada pada SliMS guna mengoptimalisasikan pelayanan pada perpustakaan SMK S Ismailiyah Rambah Hilir.

\section{DAFTAR RUJUKAN}

1. A. Pro Adhana Mengsteab and T. W. Araya, "Designing Web-based Library Management System Tsega Weldu Araya," International Journal of Engineering Research \& Technology (IJERT), vol. 9, no. 10, pp. 272-277, 2020, [Online]. Available: www.ijert.org

2. Afrizal, "Mengenal Koleksi Perpustakaan," Jurnal Imam Bonjol: Kajian Ilmu Informasi dan Perpustakaan, vol. 3, no. 2, 2019.

3. A. Nurhayati, "Perkembangan Perpustakaan dalam Pemenuhan Kebutuhan Informasi Masyarakat," Jurnal Perpustakaan, vol. 9, no. 1, pp. 21-32, 2018, [Online]. Available: http://creativecommons.org/license/by-sa/4.0/

4. Junaeti and A. Arwani, "Peranan Perpustakaan Dalam Meningkatkan Kualitas Perguruan Tinggi (Konstruksi Pelayanan, Strategi, dan Citra Perpustakaan)," Libraria, vol. 4, no. 1, 2016.

5. P. Swanson, "Building a culture of resilience in libraries," Information Technology and Libraries, vol. 40, no. 3. American Library Association, Sep. 20, 2021. doi: 10.6017/ital.v40i3.13781.

6. Fadli, "PEMANFAATAN PERPUSTAKAAN SEBAGAI TREND DALAM PEMBELAJARAN MANDIRI DI PERGURUAN TINGGI," Jurnal Ilmu Perpustakaan \& Kearsipan Khizanah AlHikmah, vol. 2, no. 2, pp. 139-145, 2014.

7. N. Hendri and S. Anugrah, "PENGEMBANGAN DIGITAL LIBRARY MENGGUNAKAN SENAYAN LIBRARY MANAGEMENT SYSTEM (SLIMS) DI LABORATORIUM 
MEJUAJUA: Jurnal Pengabdian Kepada Masyarakat Vol 1 No 2, Desember 2021

MULTIMEDIA JURUSAN KTP FIP UNP,” E-Tech, vol. 6, no. 1, 2018, doi: 10.1007/XXXXXXXX-0000-00.

8. O. Nur Amalia and L. Christiani, "ANALISIS TINGKAT KEPUASAN PEMUSTAKA TERHADAP KUALITAS PELAYANAN PERPUSTAKAAN DENGAN METODE LIBQUAL+TM."

9. E. Setyo Budi and Y. Yoga Prasetyawan, "IMPLEMENTASI SENAYAN LIBRARY MANAGEMENT SYSTEM (SLiMS) PADA PENGELOLAAN ARSIP KORAN SUARA MERDEKA," Jurnal Ilmu Perpustakaan, vol. 8, no. 1, 2019, [Online]. Available: https://texashistory.unt.edu/.

10. Shanmugam A P and Ramalakshmi, "Library Management System," Journal of Xi' an University of Architecture \& Technology, vol. 12, no. 11, pp. 743-753, 2020 